\title{
Revista

\section{¿Para qué sirve una Constitución Política en América Latina?}

\author{
Gonzalo Delamaza \\ Universidad de los Lagos, Santiago, Chile. \\ Email: gonzalo.delamaza@ulagos.cl \\ Claudia Heiss \\ Universidad de Chile, Santiago, Chile \\ Email: cheiss@iap.uchile.cl \\ Yanina Welp \\ Graduate Institute, Ginebra, Suiza. \\ Email: yanina.welp@graduateinstitute.ch
}

Como citar:

Delamaza, G., Heiss, C., y Welp, Y. (2021). ¿Para qué sirve una Constitución Política en América Latina?. Polis Revista Latinoamericana, 20 (58), 2-21.

Los últimos treinta años han sido pródigos en materia de nuevas constituciones en muchos países de América Latina: Brasil en 1988, Colombia en 1991, Argentina en 1994, Venezuela en 1999, Ecuador en 2008 y Bolivia en 2009. Todas ellas se promulgaron con el fin de promover transformaciones importantes en sus países y sociedades. Mucho más recientemente en Chile se canalizó gran parte de la enorme, diversa e intensa movilización social de fines del 2019 hacia un plebiscito en el cual porcentajes cercanos al 80\% de los votantes decidieron que se requiere una nueva constitución que reemplace a la dictatorial de 1980 y que esta debe ser. elaborada por una Convención Constituyente completamente electa a tal fin. En las constituciones políticas convergen las esperanzas de transformación. Y complementariamente, en el caso de Chile, se considera que el "cerrojo constitucional" es justamente lo que impide el cambio.

El denominado "nuevo constitucionalismo latinoamericano" designa esta tendencia de los últimos decenios a elaborar nuevas cartas constitucionales. Google académico nos ofrece 21.400 referencias a artículos sobre este tema. Sin embargo, al mismo tiempo Roberto Gargarella nos previene sobre una cuestión fundamental ¿̇cuán nuevo es el "nuevo constitucionalismo latinoamericano? (Gargarella, 2015). Sostiene que no lo es tanto y que las constituciones "nuevas" heredan de las antiguas constituciones gran parte de lo relativo a la consagración de un poder centralizado y vertical, tributario de las del siglo XIX de raíz autoritaria (entre ellas la chilena) y también lo relativo al listado de derechos que buscan garantizar, que provendría de las modificaciones realizadas en el siglo XX, a partir de la Revolución Mexicana, solo que ahora incorporando nuevos sujetos. Pero, las reglas del juego afectan la distribución del poder, por lo que no sorprende que cueste modificarlas cuando 
no hay cambios relevantes en dicha distribución. En Chile las supermayorías requeridas para el cambio constitucional y el sistema electoral binominal (eliminado en 2015) operaron como cerrojos. (Heiss, 2016; Soto y Welp, 2017).

\section{Un debate político y social}

El planteamiento anterior nos permite establecer un punto de partida sólido para el Lente de Aproximación que aquí presentamos. No nos referimos a un debate sobre la técnica jurídica. La pregunta que nos planteamos tiene que ver con la democratización y la inclusión que buscan quienes desean transformar la sociedad latinoamericana y se inscribe en una incipiente corriente de estudios que busca dar cuenta de estas cuestiones (Reuchamps y Suiter, 2016; Ginsburg etal., 2009; Contiades y Fotiadu, 2016; WelpySoto, 2019). ¿̇Sirven para ello las constituciones? ¿Cuál ha sido la experiencia en los diferentes países? Si Brasil y Colombia las promulgaron hace treinta años y los gobiernos "bolivarianos" hace veinte (Venezuela) o más de diez (Ecuador y Bolivia), ya tenemos resultados para exhibir y datos para analizar y comparar. ¿De qué depende la mayor o menor efectividad o poder democratizador de una nueva constitución? ¿Qué importancia tiene el "momento constituyente"? ¿ Cómo se relaciona el "listado de los derechos" que va creciendo con el ejercicio real del poder con la "sala de máquinas" que parece más difícil de modificar? Por último, ¿̇cuáles son las condiciones de deliberación que condicionan la elaboración y efectividad constitucional?

El enfoque adoptado en los trabajos en este marco de reflexiones no es la evaluación de las constituciones en nombre de un "ideal normativo", sino más bien el análisis de la experiencia reciente en sus virtudes y dificultades con el fin de consolidar el aprendizaje político que de ella emana. Por una parte, POLIS, Revista Latinoamericana espera contribuir con este número a extraer lecciones que puedan servir como antecedentes del proceso constituyente que se está desarrollando en Chile. Puesto que en el caso de este país organizar una Convención o Asamblea Constituyente, representa una novedad absoluta, será la primera vez que ocurra en su historia republicana. Y, por otra parte, en Chile, hasta hoy todas las constituciones se han inspirado en la tradición tanto conservadora como liberal europea, nunca mirando a América Latina. Nuestro otro objetivo es contribuir a una reflexión sobre la forma de avanzar hacia aquello que puede dar continuidad, legitimidad y eficacia a cualquier constitución democrática, que no es su "perfección", sino su capacidad de encarnar las aspiraciones mayoritarias de los pueblos. Un desafío completamente vigente en la región.

En esta introducción al Lente de Aproximación comenzaremos por hacer un análisis tipológico de las condiciones de la deliberación en los procesos constituyentes, conscientes que, en las condiciones actuales, se trata de un aspecto clave del proceso. Luego haremos una síntesis del proceso chileno, que en cierto modo podría anunciar un nuevo ciclo de 
"momentos constituyentes", surgidos de la movilización popular, pero no canalizados por agrupaciones políticas organizadas. Finalmente presentamos los trabajos que forman parte de esta publicación.

\section{Una apuesta genuina por la participación ciudadana constituyente}

¿Qué rol se ha adjudicado a la deliberación ciudadana en procesos constituyentes? A continuación, se presentan unas reflexiones basadas en la investigación de estos procesos, con una intención crítica, pero no para descartar la deliberación, a la luz de la poca importancia que ha tenido en términos de incidencia en los textos constitucionales, sino para invitar a revisar y redefinir los criterios que deberían cumplir estas instancias para ser más democráticas, justas y relevantes.

La noción de pueblo y la idea de su acuerdo tácito o explícito en un pacto fundante que da origen al estado hunde sus raíces en la filosofía política. El imaginario del constitucionalismo moderno descansa sobre el papel fundador del pueblo expresado en un texto constitucional (Elster, 1995; Negretto, 2018). La doctrina jurídica ha elaborado una serie de nociones que buscan darfundamento a ese imprescindible acuerdo ciudadano en un estado democrático, pero lo ha hecho en torno a la representación y/o a la ratificación de los acuerdos alcanzados por las autoridades, idealmente electas, a veces nominadas por el poder ejecutivo. Las cosas han comenzado a cambiar, porque los acuerdos a puertas cerradas o incluso abiertos, pero entre unos pocos, ya no se perciben como legítimos y no resultan aceptables ni son aceptados por la ciudadanía. El declive de la confianza en los partidos políticos y en los parlamentos, las crisis económicas y/o los estallidos sociales han abierto una nueva vía en las reflexiones tanto sobre el rol de la constitución como sobre la intervención directa de la ciudadanía en su elaboración. Retomaremos este punto más adelante.

Que la participación ciudadana directa en los procesos constituyentes ha cobrado relevancia se hace evidente en el número de estudios dedicados al tema (Einsestadt et al., 2017; Saati, 2015; Soto y Welp, 2017; Contiades y Fotiadou. 2016; Reuchamps y Suiter 2016, Welp 2018). Ginsburg et al. (2009), por ejemplo, asumen que las constituciones ganan peso cuando se elaboran en contextos extraordinarios de movilización popular, que incluyen procesos extra-parlamentarios de ratificación y comunicación. Sin embargo, existe controversia sobre los criterios que definen el éxito de una constitución. Las causas y factores que garantizan un diseño constitucional óptimo y las claves de su éxito -según Elster (1995) una constitución perdurable, legitimada, capaz de dar respuestas y/o un marco apropiado y compartido para la resolución de conflictos- permanecen en discusión, aunque una extensa bibliografía da pistas importantes en este camino. Quisiéramos aquí reflexionar sobre el deber ser, por un lado, y sobre el rol efectivamente atribuido de la ciudadanía en las instancias deliberativas, por otro. 
El foco en la deliberación no obedece a asumir que los procesos deliberativos tendrán consecuencias positivas por defecto en el resultado final sino a la inquietud por lo que hemos observado como una especie de "caja negra" cargada de expectativas, comparables en alguna medida a las expectativas de transformación puestas en el cambio constitucional. Mientras lo segundo viene de lejos, la expectativa de elaborar constituciones participativas es más novedosa. Es novedosa en su expansión global, pero no es nueva, y al igual que la elaboración constitucional, invita a salir de la consigna abstracta para discutir y analizar el rol de los mecanismos específicos que la materializan.

En contextos críticos, como son los que caracterizan a los procesos de descolonización, cambio de régimen, transición a la democracia y pacificación interna ha sido frecuente encontrar procesos de participación ciudadana impulsados en especial por instituciones internacionales como Naciones Unidas (UN), el Instituto de Naciones Unidas para la Paz (USIP, por sus siglas en inglés) o el Institute for Democracy and Electoral Assistance (IDEA internacional) (véase Hart, 2003; Ghai, 2006; Gluck y Ballou, 2014). Saati (2015) ha resaltado la medida en que muchos de estos procesos no superan estándares mínimos, convirtiéndose en poco más que ejercicios rápidos, controlados y meramente simbólicos. Más cerca en el tiempo, la promoción de instancias de deliberación ciudadana en los procesos constituyentes se ha extendido también a contextos democráticos en los que el cambio constitucional carga con la expectativa de resolver crisis profundas (como en Islandia en 2011 o en Chile actual), haciendo extensiva la necesidad de una reflexión al respecto.'

\section{¿Cómo caracterizar la deliberación ciudadana asociada a procesos constituyentes?}

Dejando a un lado los resultados (asociados al contexto) y centrándonos en el procedimiento (asociado al mecanismo), Welp y Soto (2019) proponen que el carácter democrático de los procesos constituyentes deliberativos está determinado por 1) el mecanismo de participación: en particular el acceso a información, el tiempo otorgado a la deliberación, la inclusión de diversidad de actores y la pluralidad de posiciones. Estos aspectos son claves para explicar que se produzca o no una deliberación informada, abierta y plural, pero no bastan. Cabe considerar también 2) el método de procesamiento de contenidos: si existe o no, si ha sido definido previamente, si permite o no la trazabilidad de resultados y está o no controlado por el gobierno. Lo que nuestra distinción analítica entre la instancia participativa y la instancia de procesamiento de contenidos pone en foco es que puede ocurrir que la participación sea plural y masiva pero luego no tener conexión con el proceso constituyente, corriendo el riesgo de volverse un puro ejercicio de movilización o una apelación vacía a la participación.

\footnotetext{
1 Esta exploración fue iniciada por Yanina Welp y Francisco Soto, al observar que abundaban los estudios de caso centrados en procesos constituyentes varios, incluyendo sus capítulos participativos, pero poco se había avanzado en la definición de criterios para evaluar esos procesos participativos en perspectiva comparada y/o en relación a unos estándares mínimos predefinidos. Con esta intención, los autores proponen una serie de criterios y realizan un análisis empírico cuyas conclusiones resumimos aquí (Welp y Soto 2019).
} 
El análisis de la trazabilidad (la posibilidad de observar los contenidos generados para seguir su recorrido durante el proceso constituyente) no presupone una aprobación automática de las propuestas ciudadanas, sino que apunta a identificar su tratamiento. Ese tratamiento diferencia un puro ejercicio retórico de un procedimiento con (mayor o menor) sentido, que habilita canales de diálogo, intercambio y rendimiento de cuentas. Consideramos que la trazabilidad es una condición (necesaria pero no suficiente, como muestra el proceso chileno de 2016, analizado por Figueroa y Jordán en este número) para la incidencia. Si no hay informes del proceso participativo, no es posible observar si la discusión constitucional incorporó temáticas provenientes de la participación al debate constituyente (en el caso chileno el proceso quedó trunco al no elaborarse la constitución en el plazo inicialmente previsto). Luego, diferentes métodos pueden garantizar que los contenidos del proceso participativo sean discutidos obligatoriamente (por ejemplo, propuestas ciudadanas respaldadas por un número determinado de firmas) o queden a criterio de las autoridades a cargo del proceso constituyente (tratamiento opcional u obligado). Si los resultados son de incorporación obligada, serán vinculantes (como ocurre con la asamblea constituyente seleccionada por sorteo en Islandia); y si esta decisión queda en manos de las autoridades, serán consultivos. La incidencia es "obligada" cuando conduce a la discusión y "opcional" cuando queda a criterio de los constituyentes la discusión específica.

Combinandoconloscriteriosparael procesamiento deinformación (másomenostransparentes y preanunciados) y el control que el gobierno ejerza sobre la institución responsable de procesar los contenidos, se califica como independiente o controlado. Así, procesos plurales y altamente participativos pueden derivar en una "cortina de humo" si al final unos pocos actores de legitimidad dudosa deciden qué entra y qué no (un ejemplo de esto sería el proceso cubano más reciente, de 2018, que analizan Chaguaceda y Viera en este número).

Al reflexionar sobre estos criterios, suponíamos que en abstracto y pensándolos en una línea continua, en un extremo del espectro encontraríamos procesos que no reunirían las condiciones para una participación plural, inclusiva y con capacidad de generación de contenidos y que tampoco contarían con mecanismos transparentes de procesamiento de los contenidos. En el otro extremo se ubicarían los procesos participativos plurales, inclusivos y con capacidad de generar contenidos, con mecanismos de procesamiento transparentes y trazables. En medio podíamos encontrar diversidad de situaciones. Por ejemplo, el control del gobierno sobre el procedimiento, que puede derivar en procesos amplios, incluyentes y participativos pero controlados, y por lo tanto sin incidencia.

\section{El rol otorgado a la deliberación ciudadana}

Para realizar el análisis empírico y testear nuestro modelo analítico seleccionamos casos ocurridos entre 1970 y 2018 en que se hubiera dado un proceso de deliberación ciudadana organizado por instancias públicas (descartamos los procedimientos privados, cuya incidencia cabe esperar y observar con otros criterios) y orientados a generar contenidos 
(no a informar o votar) y ocurrieran de forma deliberativa (no, por ejemplo, en consultas digitales individuales). En cuanto al tiempo, las instancias de participación deliberativas podían darse antes y/o durante o incluso quedar temporalmente truncas y desconectadas de un proceso constituyente efectivo, como ha ocurrido hasta ahora en el caso de Chile.

Identificados los casos (29 experiencias de nivel nacional ocurridas en 27 países), nos centramos en su diseño institucional (observamos si existía o no un procedimiento de convocatoria, a quién, cómo y cuándo se invitaba a participar) y los mecanismos para el procesamiento de los contenidos generados (si se definía o no, existían criterios para procesarlos, entre otros). Además del diseño, analizamos las prácticas efectivas (cómo ocurrieron o, en otras palabras, con qué criterios, en caso de haberlos, se sistematizó la información o se produjeron informes finales, y si se publicaron los resultados y quedaron disponibles para el público). El análisis condujo a identificar cinco tipos de procesos constituyentes participativos determinados por el tipo de participación promovida y los métodos de procesamiento de contenidos (véase la tabla 1).

Tabla 1:

Clasificación de procesos deliberativos en cambios constitucionales (1970-2018)

\begin{tabular}{|c|c|c|c|}
\hline $\begin{array}{l}\text { Mecanismo de } \\
\text { participación }\end{array}$ & $\begin{array}{l}\text { Método de procesamiento } \\
\text { de contenidos }\end{array}$ & $\begin{array}{l}\text { Caracterización } \\
\text { del proceso }\end{array}$ & Casos (29) \\
\hline $\begin{array}{l}\text { No se dan las } \\
\text { condiciones para } \\
\text { garantizar inclusividad } \\
\text { y pluralismo en la } \\
\text { participación. }\end{array}$ & $\begin{array}{l}\text { No existe un método que sea } \\
\text { informado a los participantes } \\
\text { de manera previa, ni } \\
\text { trazabilidad o incidencia } \\
\text { identificable. }\end{array}$ & $\begin{array}{l}\text { Simbólico } \\
\text { (5) }\end{array}$ & $\begin{array}{c}\text { Ruanda (2000-2003), Timor } \\
\text { Oriental (2001), Irak (2005), } \\
\text { Afganistán (2011) y Marruecos } \\
\text { (2011). }\end{array}$ \\
\hline $\begin{array}{c}\text { Se cumplen las } \\
\text { condiciones } \\
\text { de temporalidad e } \\
\text { inclusividad, pero no de } \\
\text { pluralismo, y la } \\
\text { información es sesgada. }\end{array}$ & $\begin{array}{c}\text { Se planifica la etapa } \\
\text { participativa pero no existe } \\
\text { un método de procesamiento } \\
\text { previamente informado. El } \\
\text { gobierno controla el proceso. }\end{array}$ & $\begin{array}{l}\text { Controlado } \\
\text { (5) }\end{array}$ & $\begin{array}{l}\text { Cuba (1976 y 2018), Uganda } \\
\text { (1995), Etiopía (1992-1994) y } \\
\text { Zimbawe (1999-2000). }\end{array}$ \\
\hline $\begin{array}{c}\text { Se dan las condiciones } \\
\text { de temporalidad, } \\
\text { inclusividad y relativo } \\
\text { pluralismo. }\end{array}$ & $\begin{array}{l}\text { Hay baja o nula planificación } \\
\text { del proceso, sin método claro } \\
\text { de procesamiento. }\end{array}$ & $\begin{array}{c}\text { Desborde } \\
\text { participativo } \\
\text { (3) }\end{array}$ & $\begin{array}{l}\text { Venezuela (1999), Ecuador } \\
\text { (2008), Bolivia (2006-2009) }\end{array}$ \\
\hline $\begin{array}{l}\text { Se dan las condiciones } \\
\text { de temporalidad, } \\
\text { inclusividad y pluralismo } \\
\text { y acceso a información. }\end{array}$ & $\begin{array}{l}\text { Existe un método y un } \\
\text { documento final de síntesis, } \\
\text { pero no procedimientos } \\
\text { formales que obliguen al } \\
\text { tratamiento. }\end{array}$ & $\begin{array}{c}\text { Apertura } \\
\text { participativa } \\
\text { (12) }\end{array}$ & $\begin{array}{c}\text { Colombia (1991), Nicaragua } \\
\text { (1986), Guatemala (1994-1999), } \\
\text { Sudáfrica (1994), Eritrea (1994), } \\
\text { Albania (1997), Tailandia (1997), } \\
\text { Kenia (2008), Rca dominicana } \\
\text { (2007), Zimbawe (2008-2013) y } \\
\text { Túnez (2011), Chile (2017) }\end{array}$ \\
\hline $\begin{array}{l}\text { Se dan las condiciones } \\
\text { de temporalidad, } \\
\text { inclusividad y pluralismo } \\
\text { y acceso a información. }\end{array}$ & $\begin{array}{l}\text { Existe método, organismo, } \\
\text { trazabilidad e incidencia. }\end{array}$ & $\begin{array}{l}\text { Constituyente } \\
\text { (4) }\end{array}$ & $\begin{array}{l}\text { Brasil (1988), Islandia (201 1), } \\
\text { Irlanda (2012 y 2016) }\end{array}$ \\
\hline
\end{tabular}

Fuente: Welp y Soto 2019

La combinación de resultados atribuidos a las dos dimensiones propuestas permitió clasificar cinco tipos de procesos deliberativos. Los simbólicos, los controlados, los de desborde 
participativo, los de apertura constituyente y los constituyentes propiamente dichos. En los procesos deliberativos "simbólicos" ni el mecanismo participativo ni el procedimiento de sistematización cumplieron con los requisitos mínimos. En estos, todos ocurridos en contextos sumamente críticos, de pacificación o independencia, la participación es impulsada como una forma de legitimar procesos políticos más que para incorporar contenidos a la agenda constitucional. Se incluyen aquí los procesos que tuvieron lugar en Ruanda (2000-2003), Timor Oriental (2001), Irak (2005), Afganistán (2011) y Marruecos (2011).

En los procesos "controlados", el mecanismo logró atraer un número importante de actores, fueron planificados y contaron con un tiempo para ponerse en marcha, pero el procesamiento de los contenidos fue deficitario y, sobre todo, quedó controlado por el gobierno, con distintos niveles de falta de transparencia ejemplificados por el caso de Cuba en 1976 ninguna transparencia-- y 2018 -cuando se publican documentos que permiten evaluar los contenidos generados en el proceso-como hacen Chaguaceda y Viera en este volumen. No se trata, como en el grupo anterior, de dar un barniz de legitimidad hacia afuera sino de movilizar a las bases, pero en un proceso controlado por el gobierno, sin sorpresas y sin riesgos. Se generan contenidos que pueden llegar a introducirse en el debate y en el texto constitucional pero no se especifican los procedimientos, con lo que queda a criterio de los legisladores o constituyentes (o directamente del Partido) incorporarlos en el texto final. Incluimos aquí Cuba (1976 y 2018), Uganda (1988), Etiopía (1992-1994) y Zimbawe (1999-2000).

Los procesos calificados como de "desborde participativo" se caracterizaron por ser relativamente plurales e inclusivos, pero mostrando escasa o nula planificación y aún menos métodos de procesamiento de los contenidos generados. Con este marco, observamos que los procesos de Venezuela (1999) Ecuador (2008) y Bolivia (2006-2009), que han sido destacados como experiencias que involucraron a la ciudadanía y a los movimientos sociales en el proceso, ocurrieron con escasa o nula planificación de la etapa participativa y no hubo metodologías de procesamiento de información, con lo que no cumplen los requisitos para ser considerados justos. ${ }^{2}$

Los procesos de apertura y los clasificados como constituyentes comparten casi todas las condiciones, pero se diferencian en la incidencia. Los casos de Colombia (1991), Nicaragua (1986), Guatemala (1994-1999), Sudáfrica (1994), Eritrea (1994), Albania (1997), Tailandia (1997), República Dominicana (2007), Kenia (2008), Zimbabue (2008-2013), Túnez (2011) y Chile (2017), se caracterizan por ser plurales, abiertos, independientes e informados, también se dieron con una planificación orientada a canalizar las demandas y sugerencias presentes en la sociedad civil. Sin embargo, aunque los procesos de sistematización permiten rastrear y conectar los debates ciudadanos con los constituyentes, los métodos implementados

2 La Asamblea Constituyente de Venezuela (2018 - 2020) ofrece una variante singular, ya no de desborde participativo, sino de utilización del mecanismo de asamblea ya conocido previamente, para neutralizar a la oposición política que controlaba el legislativo. Formalmente se estaba elaborando una nueva constitutición, pero una vez que la oposición perdió la mayoría en el legislativo, la Asamblea Constituyente terminó sus funciones sin proponer un texto constitucional. 
no permitieron garantizar que los debates tuvieran lugar de un modo efectivamente conectado. Esto no conduce a negar que puedan tener incidencia, pero ésta depende de la voluntad política, como ocurrió por ejemplo en Sudáfrica.

Finalmente, los procesos calificados como constituyentes sí establecen mecanismos de obligado tratamiento. Los contenidos generados por la participación ciudadana no son por defecto o automáticamente incorporados en el texto constitucional, pero sí se establece con certeza el mecanismo por el que una temática será discutida, algo que consideramos fundamental para que un proceso sea justo. Las cuatro experiencias incluidas aquí -Brasil 1988, Islandia 201 1, Irlanda 2012 y 2016 - garantizan a la ciudadanía o bien que las demandas serán tenidas en cuenta cumpliendo ciertos requisitos o, de mínima, que serán discutidas (capacidad efectiva de agenda, como en el caso de Brasil). ${ }^{3}$

\section{Implicancias sobre la deliberación en los procesos constituyentes}

Como esperábamos desde el inicio, nuestra investigación confirmó que los procesos deliberativos que han sido conducidos en contextos no democráticos y/o de altos niveles de control gubernamental tienden a no cumplir los requisitos mínimos para ser considerados como tales. Sin embargo, pudimos comprobar ahora con argumentos más claros, que otros procesos implementados en contextos democráticos también fueron profundamente deficitarios (el de Ecuador como ejemplo destacado). Esto nos ha conducido a sostener que es indispensable definir estándares para procesos deliberativos justos mientras invitamos a discutir sobre los mecanismos más apropiados para ello. Hay mecanismos muy diversos, como por ejemplo las asambleas sorteadas que pueden ser combinadas con referendos y/o procesos de deliberación que permitan generar iniciativas con respaldo de firmas, entre otros posibles. Toca abrir esa discusión.

La principal implicancia teórica del análisis presentado refiere a la propuesta de considerar que un proceso participativo debe cumplir con unos parámetros mínimos que permitan distinguir entre un mero ejercicio simbólico o instrumentalizado y un procedimiento justo, competitivo y democrático. Los promotores de la participación deliberativa deben tomar en cuenta los criterios mínimos que un proceso de estas características requiere para evitar que los mismos sigan alimentando la espiral del desencanto, porque si la ciudadanía observa que, tras un esfuerzo de movilización, aprendizaje y participación, sus aportes no son siquiera leídos, escuchados, tenidos en cuenta, o discutidos, la distancia entre representantes y representados se seguirá ampliando. Es hora de redefinir el pacto en profundidad y la ciudadanía no puede ser una mera observadora.

3 En el caso de Islandia, luego de la siguiente elección en 201 1, el poder legislativo rechazó el texto constitucional 


\section{Representación, participación y deliberación en los procesos constituyentes en tiempos de conmoción democrática}

El recuento realizado previamente en torno a la deliberación en la mayoría de los casos de los últimos treinta años muestra que esta puede adquirir diferentes características. Mirados estos procesos en nuestra región, debemos relacionarlos con los desafíos de la democracia y su evolución. Si exceptuamos el caso cubano, vemos que el último ciclo de cambios constitucionales culminó hace ya un decenio, con las constituciones "bolivarianas", clasificadas por Welp y Soto (2019) como de "desborde participativo", sin una planificación del proceso mismo y con claros déficits de accountability. Los tres procesos considerados corresponden a crisis del sistema político íntimamente ligadas a economías extractivas de petróleo o gas, altamente susceptibles a los vaivenes de la economía mundial.

En la última década no se registran otros "momentos constituyentes", puesto que el proceso de "apertura participativa" iniciado "desde arriba" por el gobierno de Bachelet en Chile en 2016, no culminó en un procesamiento legislativo del mismo, ni en el debate de una nueva constitución. ¿̇Es que en estos últimos años se han resuelto los dilemas del régimen democrático que los lleva al "momento constituyente"? Al contrario, podemos registrar numerosos antecedentes que indican un período de "conmoción democrática", que tampoco es privativo de América Latina. Las movilizaciones sociales, especialmente juveniles se han reiterado en Chile, Colombia, Guatemala y Perú. El caso chileno, ¿̇anuncia el surgimiento de un nuevo ciclo de modificaciones constitucionales sustantivas o no es más que el último caso del ciclo anterior? (como lo fue anteriormente en el ciclo de democratizaciones post dictaduras en el Cono Sur).

Por una parte, el decenio iniciado con las movilizaciones de 2011 en diversas partes del mundo ha suscitado diferentes dinámicas políticas en la región. Entre ellas el llamado "giro a la izquierda" y su reversión parcial, en sus diversas expresiones según los países (deriva autoritaria en Nicaragua y Venezuela, nuevas formas de golpes de estado en Honduras, Brasil y Bolivia, "giro a la derecha" en Chile, Argentina, Ecuador y Uruguay). Pero más allá de los vaivenes políticos, en la mayor parte de los países nombrados, así como también en México con la emergencia de Andrés Manuel López Obrador y en Perú con las sucesivas crisis políticas, se verifica una creciente tensión entre representación y participación. Los representantes son vistos crecientemente como corruptos y poco fiables. En casos como el brasileño ello ha permitido incluso el ascenso a la presidencia de un populismo de ultraderecha que pone en cuestión la Constitución de 1988 y el conjunto de mecanismos participativos usuales en Brasil. En Guatemala dio origen a un intento de incendio del Congreso Nacional.

¿Dónde han surgido presiones de cambio constitucional? El caso más destacado es el chileno, que analizamos en la sección siguiente y tomamos como ejemplo de un eventual "nuevo 
ciclo". Pero también la demanda constituyente ha aparecido en Perú, de la mano de la movilización popular, también contra la corrupción política y los intentos antidemocráticos del Congreso de dicho país. En ambos países se ha profundizado la contienda entre una democracia representativa que parece no poder gestionar las transformaciones que la sociedad demanda y una sociedad crecientemente movilizada, aunque no en los términos organizativos y políticos del pasado.

El presente y futuro próximo parecen indicar la creciente importancia de los mecanismos e instrumentos para posibilitar la participación ciudadana en los procesos constituyentes, puesto que las mediaciones tradicionales -que también tendrán que reconstruirse- no parecen funcionar del modo que lo hicieran en el pasado.

\section{¿Por qué una nueva Constitución para Chile?}

La transición a la democracia en Chile comenzó, institucionalmente, con la derrota de la dictadura cívico-militar en el plebiscito del 5 de octubre de 1988 y con la posterior aprobación, en el plebiscito del 30 de julio de 1989, de 54 reformas a la Constitución de 1980. Estas reformas eliminaron algunos de sus elementos más visiblemente incompatibles con un sistema democrático, como la proscripción de los partidos de izquierda. Sin embargo, dejaron otros intactos, como la inamovilidad de los máximos jefes militares, la existencia de senadores designados, la censura cinematográfica y el sistema electoral binominal, entre otros.

Sólo 15 años después del retorno a la democracia, en 2005, un segundo conjunto de reformas constitucionales logró reducir la función política que la Constitución asignaba a las Fuerzas Armadas en tanto guardianas del orden institucional de la república, así como eliminar los senadores designados. Esta reforma fue fruto de una negociación entre el gobierno del presidente socialista Ricardo Lagos y una oposición liderada por los herederos políticos del principal ideólogo de la Constitución, el asesor de la Junta Militar Jaime Guzmán. Al estampar su firma, Lagos afirmó que el problema constitucional estaba resuelto. Pero el problema constitucional chileno, lejos de desvanecerse, recrudeció en años posteriores (Fuentes, 2013; Heiss, 2016) hasta desembocar en la demanda por nueva Constitución que acompañó al estallido social del 18 de octubre de 2019. A pesar de que modificó en forma muy significativa el ordenamiento institucional, la reforma de 2005 se efectuó sin deliberación pública, y bajo las condiciones de la Constitución que exigían la connivencia del sector minoritario de derecha. ${ }^{4}$

En el debate político en torno a la legitimidad o ilegitimidad de la Constitución se pueden identificar al menos tres grupos: una derecha política que ve en el "pluralismo limitado" y la "democracia protegida", conceptos que animan la Constitución de 1980, una fuente de estabilidad y eficacia legitimante (Bertelsen, 2020); sectores de centro que consideran que el texto ha sido democratizado por sucesivas reformas (Ruiz-Tagle, 2016); y una

4 Ver un desarrollo más detallado de estos temas en Heiss (2020). 
izquierda que ve en la carta fundamental un instrumento de "neutralización" de la voluntad popular incompatible con el principio democrático (Busch, 2012; Atria, 2013). La idea de la neutralización se fundamenta en que los cambios políticos desde el retorno a la democracia sólo se han producido allí donde la derecha ha accedido a participar con sus votos para aprobarlos, aún sin tener las mayorías electorales para imponer su voluntad. Esto se debe a que la arquitectura institucional impuesta por la dictadura generó un rígido sistema plagado de requerimientos supra mayoritarios que hace imposible cualquier modificación sustantiva de un statu quo impuesto por la fuerza, sin la concurrencia de ese sector político. Así, todo cambio político relevante ha sido producto de acuerdos con una derecha que tiene poder de veto sobre el sistema político.

La distorsión de las preferencias ciudadanas por estos mecanismos de veto hizo imposible que las demandas y anhelos mayoritarios se vieran reflejados adecuadamente en la ley y las políticas públicas. Este bloqueo institucional de la voluntad mayoritaria contribuyó a agudizar la desconfianza en las élites, los partidos, el Congreso y las instituciones en general. La creciente desafección política se expresó en baja participación electoral, desconfianza en los partidos y el Congreso, y una continua caída de la militancia. A mediados de la década de 2000, esto derivó en un desborde institucional que generó creciente acción colectiva contenciosa a través de movimientos sociales (Somma et al., 2020) y de la judicialización de los conflictos sociales (Perricone, 2020).

El malestar con la carta fundamental se puede resumir por una combinación de tres factores: su origen autoritario e ilegítimo; la consagración de un régimen que contiene elementos reñidos con la democracia, y un sistema neoliberal deficitario en materia de derechos económicos y sociales (Busch, 2012). A partir del estallido social de 2019, se organizaron numerosos cabildos para conversar sobre el cambio constitucional. La ciudadanía pareció establecer una clara vinculación entre las instituciones políticas que determinan cómo se toman las decisiones públicas, y el resultado de esas decisiones.

\section{El momento constituyente chileno}

Jason Frank califica como "momento constituyente" al episodio inusual en que el alegato de hablar en nombre del pueblo tiene eco, se vuelve políticamente plausible y permite romper con los procedimientos de la política ordinaria sin perder el carácter democrático (Frank 2010). La idea de momento constituyente proviene de identificar un modelo dual de constitucionalismo, donde corren por vías paralelas la política ordinaria -normas elaboradas por representantes principalmente en el Congreso- y la política constituyente, que pertenece al pueblo y no a su expresión institucional. La política constituyente es un fenómeno extraordinario, que ocurre con poca frecuencia y remece los cimientos mismos de los acuerdos políticos fundamentales (Ackerman 1991).

La demanda por nueva Constitución, que adquirió fuerza tras el estallido de octubre de 2019, se encontraba ya presente en la sociedad chilena años antes. Para la campaña 
presidencial de 2013 surgió el grupo "Marca AC" que, emulando al movimiento por la Séptima Papeleta de Colombia en 1990, proponía marcar el voto con la sigla A.C., "Asamblea Constituyente", a fin de presionar al sistema político por un reemplazo constitucional. La candidata de la Nueva Mayoría, Michelle Bachelet, incluyó como una de las tres prioridades de su programa de gobierno 2014-2018 realizar un proceso constituyente, junto con la reforma tributaria y de la educación.

La etapa participativa del proceso constituyente impulsado por el gobierno de Bachelet convocó a más de 200 mil personas en encuentros locales y cabildos provinciales y regionales. La OCDE evaluó como alto este nivel de participación, en un contexto de desafección política, y lo situó entre las experiencias de mayor participación en procesos constituyentes en el mundo. Asimismo, calificó el proceso como abierto y transparente; sin embargo, también señaló que era muy difícil procesar ese volumen de información y que esta etapa no había tenido real incidencia en la propuesta de nueva Constitución del gobierno (OECD, 2017; Heiss, 2018). Dicho proceso quedó trunco tras el triunfo de Sebastián Piñera en las elecciones presidenciales de 2017. Ver al respecto el trabajo de Figueroa y Jordán en este número.

Un mes después de las protestas que se iniciaron en todo el país en octubre de 2019, la mayoría de los partidos políticos acordaron una salida institucional a la crisis a través del "Acuerdo por la paz social y la nueva Constitución". Este se tradujo en el plebiscito octubre de 2020 y un cronograma que incluye la elección de la Convención Constitucional en abril de 2021 y un plebiscito de ratificación de la nueva Carta Fundamental el 2022. La abrumadora preferencia del 78,28 \% de los votos a favor del cambio constitucional, contra sólo 21,72 \% por el rechazo, deja fuera de duda la crisis de legitimidad de la Constitución de 1980 y la existencia de un momento constituyente.

La distancia entre élites y ciudadanía, sumada a las distorsiones y exclusiones del sistema de representación política, ha agudizado una crisis de la política institucional, la que se ha vuelto incapaz de canalizar el conflicto para traducirlo en pluralismo político. La desprotección social que se mantuvo en contra de la voluntad ciudadana durante décadas llevó al estallido de octubre. Pero las demandas de esta movilización no se reducen a la redistribución en el plano económico; también incluyen una redistribución del poder político que acerque las decisiones a la ciudadanía, desconcentre funcional y territorialmente el poder y corrija a través de acción afirmativa la exclusión de diversas categorías de ciudadanas y ciudadanos. Los avances que, en este sentido, significan la paridad de género para la elección de la Convención Constitucional y la existencia de escaños reservados para pueblos indígenas, son un indicio de la relación entre mecanismo y resultado. Es por eso que la transparencia y la apertura de la Convención a la deliberación pública serán fundamentales no sólo para la democratización del sistema político regulado por la Constitución de 2022, sino para su representatividad y legitimidad de origen (Delamaza, 2020). 


\section{Procedimientos, resultados y contextos en constituciones latinoamericanas}

Este número de Polis. Revista Latinoamericana incluye cuatro trabajos especialmente pertinentes y destacados sobre la pregunta que lo define. Ellos abordan temas tales como: a) ¿lmporta la Constitución? A lo que se responde analizando la relación entre Carta Fundamental, la legislación y las políticas públicas; la interacción con el sistema legal e interpretativo y también las tensiones y desafíos en el diseño y la implementación; b) La capacidad de las constituciones para reorganizar el sistema económico en un sentido inclusivo y sustentable; c) La representatividad, y más concretamente, ¿̇si se ha logrado la consolidación jurídica de una hegemonía basada en los intereses de las grandes mayorías?; y d) La importancia política del "momento constituyente" y sus consecuencias en términos de "path dependence". La convocatoria de POLIS Revista Latinoamericana a escribir sobre ¿para qué sirve una constitución en América Latina? tuvo una amplia respuesta desde el mundo académico, recibiéndose 17 trabajos que consideramos pertinentes a la misma, provenientes de diferentes países. De tal manera que creemos que el interés por el tema existe. Sin embargo, el riguroso proceso de evaluación de pares que utilizamos nos reveló una cierta debilidad en el tratamiento del tema constitucional que nos parece importante mencionar.

En el primer trabajo del volumen, Inclusión de derechos indígenas en Chile: Arquetipo constituyente desde América Latina, de Carolina Acevedo De La Harpe, la autora introduce la perspectiva comparada con el fin de aportar evidencia latinoamericana que contribuya al diseño del cambio constitucional chileno. Se trata de una problemática típicamente latinoamericana, que en Chile ha motivado una innovación histórica (además de las ya mencionadas previamente), cual es la reserva de 17 escaños para ocho pueblos indígenas dentro de un total de 155 constituyentes. Vale decir un porcentaje bastante aproximado a la población que se autodefinió como indígena en el Censo de 2017. Su propósito es abordar una problemática que sólo puede dirimirse en el contexto constitucional, para lo cual la participación directa de los pueblos resulta fundamental.

En el artículo, sobre la base de un análisis cualitativo comparado (QCA) de 15 países, busca entender cómo los factores institucionales, políticos y sociales han sido determinantes para explicar un arquetipo de reconocimiento de derechos exitoso para los pueblos indígenas en América Latina. Los resultados del análisis muestran que el tipo de mecanismo institucional para el cambio de la constitución, en particular la asamblea/convención constituyente y la participación de los movimientos indígenas, a través de escaños reservados y de movimientos sociales, son necesarios para explicar la obtención de mayores derechos indígenas en las constituciones. El tipo de crisis y proceso político que llevó a estas negociaciones es en gran medida la explicación de que los factores mencionados fuesen determinantes. Así, la autora señala que "este marco de negociaciones interinstitucionales y de movilizaciones permitió pensar en una forma distinta de convivencia para los Estados y sus pueblos indígenas, una 
donde la orientación política del Estado reconociese mediante norma y política pública la diversidad cultural redefiniendo lo que se entendía por comunidad política, Estado-nación y convivencia social".

La diversidad de resultados en los países considerados se analiza en base a información secundaria ya tratada por otros autores. El esfuerzo del trabajo es vincular los diferentes orígenes del proceso -crisis institucional, rol de los actores políticos y crisis social- con los procedimientos utilizados para el cambio constitucional y el rol de los pueblos indígenas en estos procesos. Ese cruce permite seleccionar los factores ya mencionados como más relevantes en diferentes configuraciones que a su vez agrupan a varios países. La autora profundiza en los casos de Bolivia y Colombia como ejemplo de dos de las principales configuraciones establecidas.

Un segundo trabajo aborda en profundidad el impacto relativo que tienen las constituciones en determinados ámbitos de política y gestión de lo público una vez en aplicación. En este caso la descentralización, para lo cual toma como ejemplo uno de los casos más mencionados como descentralizadores, cual es el de Colombia en la constitución de 1991. Se trata de la economía como argumento constitucional. El caso de la descentralización fiscal en Colombia, de Alejandro Angel. El artículo parte del hecho que la Constitución de 1991 estableció que Colombia se organizaba en forma de República unitaria, descentralizada y con autonomía de sus entidades territoriales. Diez años después de promulgada la constitución, en un momento de profunda crisis económica y fiscal, hubo una reforma sustancial al esquema de transferencias que debía hacer el gobierno central a los gobiernos subnacionales, que le permitió al primero recuperar buena parte de los recursos fiscales que habían sido destinados a los gobiernos territoriales. El argumento del autor es que, de la misma forma que las constituciones en América Latina se mueven al vaivén de las coaliciones partidarias, la constitución colombiana se cambió al vaivén de la economía. Esto le permitió al gobierno central retomar los recursos que había cedido por las reformas constitucionales sin necesariamente resolver definitivamente el déficit fiscal.

El artículo enfatiza en el rol de la economía y sus transformaciones, algo que ha sido poco estudiado en relación al cambio constitucional. "Así como los equilibrios partidarios son importantes para entender los diseños institucionales y sus posibles alcances, la coyuntura económica también es importante para entender las posibilidades de cambio perenne que las constituciones pueden aportar en América Latina". En este caso la coyuntura cambió a partir de la nueva constitución, lo que permitió la reversión relativa de los cambios introducidos. El punto es relevante, toda vez que la constituyente de 1991 profundizó un proceso histórico previo y en ello no fue tan innovadora como en otros campos. Pero no logró resolver la relación entre esta profundización y la economía, en particular las finanzas públicas. Señala el autor "en la práctica, esto muestra que la Asamblea Constituyente que promulgó en 1991 una nueva constitución en la que hubo importantes avances en multiplicidad de arenas -e.g., una generosa carta de derechos, el reconocimiento del carácter pluriétnico y multicultural de la nación colombiana, entre otras - no logró zanjar el debate 
político acerca del significado de la descentralización política y de recursos económicos en Colombia. De hecho, (...), numerosos actores argumentaron que la razón del debilitamiento de las finanzas públicas colombianas a lo largo de la década de 1990 fueron las transferencias de recursos a los gobiernos subnacionales". Llegado el momento, ello significó que el consenso inicial varió en favor de una recentralización de los recursos fiscales.

El tercer trabajo resulta especialmente relevante por el déficit analítico que existe en relación al caso cubano en la reflexión constitucional latinoamericana. Cuba vivió un proceso constituyente en 1976 y otro en 2018, el cual es analizado en el trabajo titulado El destino

de Sísifo. Régimen político y nueva Constitución en Cuba, de Armando Chaguaceda y Eloy Viera Cañive. El artículo aborda las transformaciones y persistencias político- institucionales, enmarcadas en el proceso de debate y aprobación de una nueva Constitución en Cuba. Se ubica la experiencia dentro de la familia de los constitucionalismos autocráticos, específicamente en su modalidad soviética. Se analiza el caso a partir de los elementos estructurales del régimen (post)totalitario estableciendo diversas categorías del mismo, los que se ponen en relación con las reformas e innovaciones legales aprobadas en la nueva Carta Magna. Al final, se evalúan las posibilidades que el nuevo marco constitucional ofrece para un mayor empoderamiento ciudadano, de cara a las demandas sociales y las transformaciones pendientes del modelo cubano.

El trabajo incluye un análisis histórico del constitucionalismo en el período revolucionario, señalando que la constitución de 1976 "constituyó el símbolo del final del proceso de institucionalización de la Revolución Cubana. Un proceso que no fue diseñado por una Asamblea Constituyente como en 1901 cuando se construyó la institucionalidad de la naciente República cubana o como en 1940 cuando se reformó". La carta constitucional del 76, promulgada 17 años después del triunfo de la revolución por las armas, permitió - de acuerdo a los autores- institucionalizar el régimen, pero no limitar el alcance de su acción política, puesto que se desarrollaron múltiples iniciativas que no se sujetaban al texto aprobado sino a la voluntad y necesidades políticas del liderazgo carismático de Fidel Castro. El proceso de institucionalización que se inicia que el traspaso del poder político a su hermano Raúl en 2013, cuyo período fue definido por el mismo como de cinco años sin reelección, llevó a una nueva constitución, aun cuando ello no estuvo presente como meta inicial. Pero la evolución del proceso y en especial sus necesidades de vinculación con el exterior (Unión Europea) llevaron al proceso de 2018 - 2019. El artículo analiza el diseño encabezado por Raúl Castro que apunta a asegurar la hegemonía del Partido Comunista en el marco de una jefatura de Estado que va cambiando de titular.

Se realiza un pormenorizado análisis de las condiciones y resultados tanto del proceso de debate con la población, a través de miles de encuentros en centros laborales, estudiantiles y otros, así como del referéndum sancionatorio al que fue sometido el texto. A pesar de la masividad de ambos procesos, los estándares de libertad de expresión y real debate distan significativamente de los esperables en un proceso de democratización. Finalmente, el tra- 
bajo analiza la continuidad de la "sala de máquinas" del texto constitucional, que concluyen permanece intacta. A ello se suma la reafirmación del predominio del partido Comunista como titular del poder y el uso de otras normas legales con que el Estado actúa, independientemente del texto de la constitución. A modo de conclusión los autores establecen que "la aprobación de la Constitución de 2019 no ha variado la esencia post totalitaria del régimen cubano. No habilita canales que realmente permitan a la ciudadanía utilizar sus normas e instituciones para participar autónomamente y limitar los poderes de un Estado autocrático".

Finalmente ofrecemos un texto sobre el caso chileno, pero relativo al proceso que antecedió al actual de cambio constitucional. Los autores, directamente involucrados en el diseño y ejecución del intento de elaboración de una nueva constitución como iniciativa del segundo gobierno de Michelle Bachelet en 2016, realizan un profundo análisis del mismo, ofreciendo sobre todo una visión sobre el proceso participativo que involucró. Se trata de

Convergencia Deliberativa: La participación ciudadana en el cambio constitucional, Chile 2016, de Pamela Figueroa Rubio y Tomás Jordán Díaz. El trabajo examina la fase participativa del denominado Proceso Constituyente Abierto a la Ciudadanía en Chile (2016), como metodología para el cambio constitucional.

Partiendo de la base de investigaciones que señalan que el proceso de cambio constitucional es clave en los resultados esperados y que la metodología participativa importa, el trabajo se inicia con un examen del proceso histórico político que llevó a un incremento de la demanda por el cambio constitucional y a la respuesta intentada por el gobierno de Bachelet. Se analiza con detalle el enfoque y la metodología empleada, de innegable matriz habermasiana. Así, se establece que "se propuso para la deliberación pública una metodología especial, diseñada por el Gobierno, para el desarrollo de las conversaciones constitucionales. La Convergencia Deliberativa concibe el proceso como un espacio mediante el cual las personas desarrollan conversaciones (deliberación) a partir de distintas posiciones, y llegan a conclusiones o puntos en común (convergencia), de manera colaborativa, para definir acuerdos, acverdos parciales o desacuerdos sobre los asuntos constitucionales. La convergencia deliberativa tiene dos componentes: la convergencia entendida como acto de cooperación para la búsqueda de puntos en común, y la deliberación, entendida como el diálogo a partir de distintas posiciones, evaluando las ventajas y desventajas, en la construcción de acuerdos o decisiones. Deliberar es reflexionar colectivamente sobre alternativas para tomar una decisión conjunta y configurar un acuerdo. Esta combina elementos conceptuales, como la cooperación y la legitimidad; elementos metodológicos, como el diálogo en torno a temáticas concretas con el apoyo de los facilitadores, y elementos simbólicos de encuentro, cohesión y experiencia de logro compartida."

Sobre la base de los conceptos establecidos el artículo analiza detalladamente la fase participativa del proceso constituyente, tanto en su diseño como en sus resultados (encuentros, cabildos, sistematización, elaboración de Bases Ciudadanas Constitucionales y proyecto de nueva constitución) y mecanismos de contraloría y observación externa (Datos abiertos, Consejo Ciudadano de Observadores). Se realiza también una comparación 
con las magnitudes de participación en otros procesos constitucionales, que ubica a este proceso en una categoría de alta participación. En sus conclusiones se señala que, a pesar del esfuerzo realizado, "debido a la ausencia de un acuerdo político amplio por el cambio constitucional durante el gobierno de la presidenta Michelle Bachelet (2014-2018), que acompañara el amplio acuerdo social por el cambio constitucional; y al cambio de gobierno en marzo de 2018, donde asume como presidente Sebastián Piñera, el proceso constituyente queda suspendido". La coyuntura actual posterior a 2019 en Chile, permite considerar el proceso como un antecedente que en parte es retomado en el país, a partir de la presión "desde abajo".

Una vez más los casos de Cuba y Chile, tal como aquí son analizados, muestran paralelismos que realzan sus contrastes políticos. En la primera, un régimen sin fisuras impuso una Constitución en 1976 y otra recientemente. En ambos casos son textos que se acomodan a sus propósitos. Logra aprobarlos en breve plazo gracias a su inmenso poder y en el caso reciente lo procesa a través de mecanismos participativos de bajo estándar y fuerte control. En Chile, en cambio, luego de la vigencia por más de treinta años de la Constitución de Pinochet, el gobierno de Bachelet II, conformado por una amplia y heterogénea coalición, intenta un proceso abierto a la ciudadanía que, sin embargo, no logra superar las barreras del régimen político negociado con la dictadura veinticinco años antes. La continuidad del régimen cubano, sin embargo, se revela hasta hoy como mayor que la del chileno, aun sin abrir espacios genuinos a la expresión ciudadana. Puesto que el contexto democrático del país sureño permitió el ascenso de la movilización social y obligó a la apertura de un proceso de deliberación constitucional que comenzó desde abajo y se proyecta actualmente en una Convención Constitucional electa, paritaria y con escaños reservados para los pueblos originarios. No es Chile el único país que experimentó "estallidos sociales" en 2019, los que también ocurrieronen Colombia, Líbanoyotroslugares. Peroeselúnico que, hasta elmomento, intenta canalizar dichas presiones a través de un cambio constitucional significativo. Así las constituciones sirven para diferentes fines en relación al régimen político, dependiendo tanto de la vigencia de la democracia como del dinamismo de las fuerzas sociales.

Por otra parte, los trabajos de Acevedo y Angel muestran modos distintos de analizar el resultado que obtienen las constituciones. El trabajo de Acevedo permite alimentar la reflexión comparada en cuanto al diseño de las constituciones en relación a la participación indígena, estableciendo con claridad que tanto el contexto institucional previo como las modalidades de involucración de los propios actores son relevantes a la hora de obtener logros para los pueblos indígenas en la redacción de los textos constitucionales. Angel, por su parte, sitúa su análisis en la fase de implementación de la constitución, demostrando que estos documentos, aunque jurídicamente preeminentes en la tradición republicana, también se modifican según lo hacen las coyunturas económicas de los países. Vale decir, son influidos por el proceso económico, así como por el proceso político. Ambos trabajos ejemplifican dos formas de evaluar el resultado de los procesos constituyentes, alimentando la respuesta a nuestra pregunta inicial, ¿̇para qué sirve una constitución en América Latina? 


\section{Agradecimientos}

Los autores agradecen el apoyo del Proyecto Fondecyt Regular 1180496.

\section{Bibliografía}

Ackerman, B. (1991). We the People: Vol I, Foundations. Cambridge MA: Belknap Press.

Atria, F. (2013). La constitución tramposa. Santiago, Chile: LOM.

Bertelsen, R. (2020). En Defensa de la Constitución. Santiago, Chile: Thomson Reuters.

Blount, J. (2011). Participation in Constitutional Design, en Ginsburg, T.y R.Dixon (eds.) Comparative Constitutional Law. Edward Elgar.

Busch, T. (2012). El concepto de Constitución y la incomodidad constitucional en Chile. Global Jurist, 12(2). DOI: 10.1515/1934-2640.1410

Contiades, X y Alkmene,F. (2016).Participatory Constitutional Change: The People as Amenders of the Constitution. Nueva York, USA: Routledge.

Delamaza, G. (2020) La participación ciudadana en el proceso constituyente. Santiago: Plataforma Contexto. Recuperado de: https://plataformacontexto. $\mathrm{cl} / \mathrm{recurso} / 111$

Einsenstadt, T, Carl LeVan,A y Tofigh, M.(2017). Constituents before Assembly. Cambridge, UK: University Press.

Elster, J. (1995). Forces and Mechanisms in the Constitution-making Process, Duke Law Review 45 (2): 364-96.

Frank, J. (2010). Constituent Moments: Enacting the People in Postrevolutionary America. Durham, USA: Duke University Press.

Fuentes S, C. (2013). El Pacto. Poder, constitución y prácticas políticas en Chile (1990-2010). Santiago, Chile: Ediciones Universidad Diego Portales.

Gargarella, R. (2015). El nuevo constitucionalismo latinoamericano. Estudios Sociales. Revista Universitaria Semestral, 48 (1), 169-174

Ghai, Y.(2006). The Role of Constituent Assemblies in Constitution Making. International IDEA. Recuperado de: http://constitutionnet.org/sites/default/ files/2017-08/the_role_of_constituent_assemblies_-_final_yg_-_200606.pdf

Ginsburg, T, Zachary, E y Justin Blount. (2009). Does the process of constitution making matter? Annual Reviews, (5) 201-223.

Hart, V. (2003). Democratic constitution making, USIP. Recuperado: https://www. usip.org/publications/2003/07/democratic-constitution-making

Heiss, C. (2016). "Soberanía popular y 'momento constituyente' en el debate sobre cambio constitucional en Chile". Anales de la Universidad de Chile. Séptima serie (10), 109-125.

. (2018). Participación política y elaboración constitucional: el caso de Chile. Derecho y crítica social, 4(1), 115-138.

Heiss, C. (2020). ¿Por qué necesitamos una nueva Constitución? Santiago, Chile: Aguilar.

Negretto, G. (2018). Democratic constitution-making bodies: The perils of a partisan convention. International Journal of Constitutional Law, 16 (1) 254-279.

OECD Public Governance Reviews. (2017). Chile Scan Report on the Citizen Participation in the Constitutional Process. URL: https://www.oecd.org/gov/ public-governance-review-chile-2017.pdf

Perricone, A. (2020). La judicialización de la protesta y sus resultados: una tipología de la movilización legal en el Chile post transición (1990-2018). Revista de Ciencia Política, 40(1), 73-94.doi http://dx.doi.org/10.4067/s0718$090 \times 2020000100073$

Reuchamps, Min y Jane Suiter (eds) (2016) Constitutional Deliberative Democracy in Europe. Colchester, UK: ECPR Press.

Ruiz-Tagle, P. (2016). Cinco repúblicas y una tradición. Constitucionalismo chileno comparado. Santiago, Chile: LOM. 
Saati, A. (2015). The Participation Myth, Outcomes of participatory constitution building processes on democracy, Department of Political Science, Sweden: Umeå University.

Somma, N., Bargsted, M., Disi Pavlic, R., y Medel Sierralta, R. (2020). "No water in the oasis: The Chilean Spring of 2019-2020". Social Movement Studies, 1-8.doi https://doi.org/10.1080/14742837.2020.1727737

Soto, Fy Yanina,W.(2017). Los 'diálogos ciudadanos'. Chile ante el giro deliberativo. Santiago, Chile: LOM.

Welp, Y. ( 2018). "¿La trampa del gatopardo? El reemplazo constitucional en los países andinos", Castellà, Josep Maria (ed.) 2018. Parlamentos, Ciudadanos y Entes Territoriales ante la Reforma Constitucional: ¿Quién y cómo participa?. Madrid, España: Editorial Tirant Lo Blanch.

Welp, Y y Soto. (2019). "Más allá de modas y cortinas de humo: la deliberación ciudadana en cambios constitucionales", Revista Española de Ciencia Política 50 13-41. 